\title{
Designing distribution centres for agile supply chains
}

\author{
PETER BAKER \\ Cranfield University, UK \\ Centre for Logistics and Supply Chain Management \\ Cranfield School of Management \\ Cranfield University \\ Bedford \\ MK43 0AL \\ United Kingdom \\ Tel: +44 1234751122 \\ Fax: +44 1234752441 \\ E-mail: peter.baker@cranfield.ac.uk
}




\section{Designing distribution centres for agile supply chains}

Increasing globalisation and market volatility represent major challenges for many supply chains, and particularly for the distribution centres within them. This paper examines how distribution centres are being designed to be agile even though they are, by their nature, longterm fixed assets. The research is based on semi-structured interviews with warehouse design companies to identify the range of agility types that were regarded as necessary during the design phase, and how these were addressed. The research also explores the cost, time and service level implications, whilst handling variances in demand or supply. The interviewee responses are expressed in terms of qualitative measures on Likert scales. The results indicate that there is generally a slightly or moderately higher cost to design for agility. Based on the literature and the case study responses, a methodology is developed of how to address agility within warehouse design, and areas of further research are identified.

Keywords: Agility; Flexibility; Distribution Centres; Warehousing.

\section{Introduction}

Distribution centres are key nodes in most supply chains, accounting for approximately $22 \%$ of total logistics costs (Establish / Davis 2005). New warehouses continue to be designed and built and there is some evidence that there is in fact an increasing trend in the building of large distribution centres (Baker 2004).

These distribution centres play a vital role in the success, or failure, of businesses (Frazelle 2002a) but they also represent significant investments with long asset lives. Owing to their size, investment is required not only in the land and buildings but also in automated 
equipment, such as conveyorised sortation equipment, so as to contain costs (Pfohl et al. 1992). However, these characteristics may be in conflict with the need for agile supply chains and there is concern in the trade press, for example, about the degree of flexibility offered by large automated warehouses (e.g. Matthews 2001 and Allen 2003).

This paper examines the concept of supply chain agility specifically in relation to the roles that distribution centres may play. Within this context, a model is developed to investigate how distribution centres may be designed to meet the requirements of agility and to examine the cost, time and service implications of these design features. The model is then developed further with six warehouse design companies to identify whether it encompasses the design features used in actual distribution centre designs. Actual design features used to address different types of agility are identified, and an outline framework is developed, which are intended to be of benefit to practitioners in the field.

\section{Supply chain agility}

There have been a number of definitions of supply chain agility and many of these reflect the aspirational nature of the concept, as noted by Stratton and Warburton 2003. One such definition is that "Agility is the basis for achieving competitive advantage in changing market conditions" (Bal et al. 1999, p.75). This definition describes the concept fairly succinctly.

Some definitions go further than just describing the overall capability of agility and list key elements that must be in place for its achievement. For example, Christopher (2000, p. 37) states that "Agility is a business-wide capability that embraces organizational structures, information systems, logistics processes, and, in particular, mindsets. A key characteristic of an agile organization is flexibility." This latter definition of agility introduces the term 
flexibility and these terms are often used interchangeably. However, in general, flexibility tends to be used at a lower (e.g. operational) level and agility tends to be used at a much more encompassing (e.g. business wide) level, for example by van Hoek (2001).

The term agility is often compared with lean supply chain concepts. However, it is generally recognised that company supply chains normally need to encompass both concepts, as both cost and service are likely to be either a market qualifier or a market winner (MasonJones et al. 2000). Indeed, hybrid approaches to supply chains may well be applicable, as explored by Christopher and Towill (2001).

The required capabilities for agile supply chains have been developed in a number of areas, but these mainly relate to organisational and information-based aspects, for example, virtual teaming (Bal et al. 1999) and information lead-times (Mason-Jones and Towill 1999). The competencies and resources required for agility at the operational level in supply chains, such as at the distribution centre level, have not yet been examined in depth.

Another categorisation used to define supply chain agility has been to divide this concept into three elements: sourcing agility, manufacturing agility, and delivery agility (Prater et al. 2001). Again, very little research has so far been conducted in the latter area, within which this paper is placed.

\section{Distribution centres within agile supply chains}

There has been a trend towards goods moving through distribution centres rather than being stored in them, thus, becoming "switching yards" rather than "holding yards" (Drucker 1992). 
This is regarded as a key part of agility in warehousing, for example by using end consumer demand to drive replenishment throughout the supply chain (Christopher 2005). A prime role of warehouses in agile supply chains has been viewed as cross docking and in-transit merging (van Hoek 2001). This cross docking (i.e. receiving and dispatching goods without putting away into storage) may be between warehouses at different levels in the supply chain, as in the case of local transhipment depots receiving goods from national distribution centres, or may be between warehouses at the same echelon level, as in the case of sharing inventory between regional distribution centres (Herer et al. 2002).

However, inventory still plays a key role in most supply chains. For example, although inventory in the manufacturing, wholesaling and retail sectors in the UK has declined as a ratio of turnover, it still represents on average between 3 and 5.5 weeks of sales in each of these sectors (Office for National Statistics 2005). In the USA, the overall ratio of inventory to sales has been reported as being static (Frazelle 2002a), whilst a study for the Warehouse Education and Research Council (WERC) has noted that warehouses are being opened to handle imports as part of global supply lines (Maltz and DeHoratius 2004). This latter report also noted the consolidation of stockholding points that is occurring.

Within the agile supply chain literature, it has been noted that it is necessary to locate inventory and capacity at strategic points to facilitate the flow of goods through the supply chain, particularly as a result of the growth of product innovation and demand uncertainty (Stratton and Warburton 2003). The increasing globalisation of supply chains also result in the need to hold increased inventories due to long, and less certain, lead times (Harrison and van Hoek 2005). 
These strategic inventory holdings are often termed "decoupling points", as they enable lean production to take place based on reasonably level output levels, separated from a downstream agile supply chain serving volatile market places (Naylor et al. 1999). These decoupling points may be at various levels in the supply chain, for example near the source of supply or the point of demand, depending on the supply chain characteristics, for example "make to stock" or "ship to stock" (Childerhouse and Towill 2000).

The requirement for decoupling points, the trend towards inventory consolidation, and the need for cross-docking and merging facilities all lead to the establishment of distribution centres, many of which need to be substantial in size to fulfil their roles.

\section{The design of distribution centres}

The design of distribution centres is normally described as a series of steps based on forecasted demand (e.g. Rushton et al. 2000 and Hassan 2002), with the objective of identifying the most efficient design for the planning horizon. These broad steps have been supported by an ethnographic study of actual warehouse designs by Bodner et al. (2002), who proposed a decision support architecture that could act as a basis for future development. The incorporation of flexibility may be regarded as implicit in these steps but no specific conceptual tools are presented. This has been partly addressed by Rowley (2000, p.4) who added a final step of "computer simulation of the proposed warehouse with different volumes and the consequences on the rest of the supply chain". However, this step does not address how to incorporate flexibility into the actual design process. 
The warehouse design process is recognised as being complex with multiple objectives and with a very large set of alternatives that is often impossible to optimise in practice (Rouwenhurst et al. 2000). The elements to be considered in the final design (taken from the references in this section) include:

- Building design: including features such as height, floor flatness and strength, climate control, sprinklers, fire walls and exits, and goods in/out doors.

- Equipment: including storage and handling equipment, ranging from automated equipment such as sortation systems through to more labour intensive equipment types, such as picking trolleys.

- Staffing: considerations include the use of permanent and temporary staff, multiskilling, ergonomics, and health and safety issues.

- Systems: including the functionality of warehouse management systems (WMS) and equipment control systems, needed to support the planned operation.

- Process design: processes are required to support the various warehouse functions of receiving, storage (or cross-docking), picking, added value services, marshalling and despatch.

The consequences of not building in flexibility into these design features can be dramatic, as exemplified by a study of e-fulfilment operations which concluded that the "suggested design may make or break an e-commerce fulfilment center" (Tarn et al. 2003, p.361).

\section{Model development}

This paper follows a general framework that has previously been used for agile supply chain research, as presented by van Hoek et al. (2001). This comprises: 
- Identifying the concept being examined (i.e. agility);

- Defining the scope or setting (in this case distribution centre design);

- Identifying the capabilities required at the operational level;

- Measuring by means of an audit or assessment;

- Presenting the operational challenges that are faced.

The broad concept of agility has been defined in the preceding sections, but, more specifically, this research focuses on the design characteristics that are used to respond to particular facets of agility. Three main facets of agility have been identified by van Hoek (2001), namely:

- Volume variance, including that caused by seasonality, product life cycles and end consumer demand fluctuations.

- Time variance, for example urgent orders.

- Quantity variance, for example orders at item, rather than case, level.

These concern the informational flows (e.g. customised information) as well as the physical flows, and may relate to the ability to respond to variances in inbound shipments as well as to variances in market demands. These definitions of agility types were used as a basis for the research, and were developed further during the interview process.

In order to be able to succeed in volatile market places, companies need to develop the flexible capabilities that are critical to their customers and support these with flexible competencies, which may include for example internal processes and infrastructure (Zhang et 
al. 2002). These capabilities and competencies span the whole value chain, but the scope for this research is focussed on that provided at the distribution centre level. This is akin to the framework set out for examining manufacturing flexibility that involves a hierarchy from strategic business unit level through to individual machine level (Koste and Malhotra 1999). At the level of the distribution centre, the necessary resources include space, materials handling equipment, labour and information systems, as well as the integration of these resources, in terms of processes (Frazelle 2002b). These are the resource categories used in this research.

Many of these resources require long development times (e.g. bespoke warehouse management systems) and long asset lives (e.g. high bay automated warehouses). They may thus provide a sustainable competitive advantage to a firm by meeting the criteria of being valuable, rare, inimitable and non-substitutable (Barney 1991), in line with the literature on the resource-based view of the firm.

Flexibility has been measured in manufacturing along three dimensions (Upton 1994) and these can be amended for distribution centre analysis as follows:

- Range, i.e. the types of agility offered, as described above, and the extent to which each type of variance can be accommodated. For example, a distribution centre may be agile in that it can respond to urgent orders but may not be able to accommodate wide variations in volume throughput.

- Mobility, i.e. the ease with which the distribution centre can move between these, in terms of cost and time. For example, Prater et al. (2001) define agility as the ability to respond within a useful timeframe, and thus the speed of adjustment is critical. 
- Uniformity, i.e. achieving constant performance and service levels whilst being flexible. Agility focuses on customer service, and thus it would generally not be acceptable to provide a capability to be able to respond rapidly to the range of variances that may occur at the expense of such service features as accuracy or order completion.

The combined literature in the areas of supply chain agility, resource based view of the firm, manufacturing flexibility and warehousing thus provides a number of approaches for examining flexible design features within distribution centres. These approaches are used in this paper to explore how distribution centres are being designed to meet the agile requirements of volatile market places, and to present a framework that may be of assistance to practitioners in meeting the challenges faced in the field.

\section{Research design}

The research was based on semi-structured interviews with six warehouse design companies, ranging from large multi-national companies with their own equipment manufacturing capabilities to small/medium sized independent warehouse design companies. The companies interviewed were: Clayden Consulting, FKI Logistex, Jigsaw Logistics, Jungheinrich, Siemens and Total Logistics. Each company was interviewed concerning the design of distribution centres that formed part of international supply chains.

In total, these comprised two Global Distribution Centres, six European Distribution Centres and three National Distribution Centres. The latter were all parts of inward international supply chains, serving a national market. The distribution centres were located 
in the UK (6 in number), Belgium (2), the Netherlands (1), Spain (1) and South Korea (1). The industries covered were clothing/footwear (4), electrical/electronics (3), furniture (1), paper (1), pharmaceuticals (1) and machine parts for the aftermarket (1). Five distribution centres were operated by (or on behalf of) manufacturers, three by wholesalers, and three by retailers. All of the distribution centres were over $10,000 \mathrm{~m}^{2}$ in floor area, with the largest being $170,000 \mathrm{~m}^{2}$. The heights varied from $10 \mathrm{~m}$ to $30 \mathrm{~m}$, with six of the distribution centres having high-bay areas over $20 \mathrm{~m}$ in height.

Each interviewee was asked to identify the degree of agility that was perceived as being required for the distribution centre in question. This was based on the three basic types of agility identified by van Hoek (2001) and expanded to include other aspects mentioned during the interviews. The interviewees were asked to provide the degree of agility required for each type of agility on a 5-point Likert scale.

Where scores of 3 or more (i.e. "average requirement" or above) were given, the interviewees were then asked to describe how they had planned for that particular type of agility. The answers were categorised under the headings of land/buildings, equipment, staffing, process and systems.

For each answer, the interviewees were then asked to give their opinion as to the impact of the planned measure on:

- Capital cost (i.e. whether the design of an agile capability had cost more in capital terms). This was measured on a 7-point Likert scale, ranging from a "3" for a significant variation (i.e. a much higher capital cost), a "0" for no impact, to a "-3" for 
a significant improvement (i.e. a much lower capital cost). This allowed for variations in both directions. The aim was to provide a qualitative assessment of the different measures, so no figures were collected. However, in discussions, a guideline of 0$10 \%$ was used for "slightly higher costs", 10-25\% for "moderately higher costs" and over $25 \%$ for "much higher costs". These were applied to the individual building, equipment, staffing, or systems costs in question.

- Operating cost (i.e. whether it would cost more in terms of annual operating costs). This was measured in the same way as capital cost.

- Mobility (i.e. how quickly it could respond to the variance in question). For this measure, a reduced range, from " 3 " for long-term to " 0 " for immediate was used (as negative figures would have been meaningless). The guidelines were zero time for immediate availability, up to 3 weeks for "short term", 3 weeks to 3 months for "medium term", and over 3 months for "long term".

- Uniformity (i.e. whether the customer service level would be maintained during this response). This was measured on a 7-point Likert scale. No quantitative guidelines were provided with regard to service levels owing to the multitude of parameters that companies measure. The service level results are therefore the subjective views of the interviewees, ranging from " 3 " for significant worsening of service levels to "- 3 " for significant improvement, compared to the levels experienced outside the period of variance in question.

\section{Results}


The different types of agility are explored first of all and then the ways in which the designers actually responded to each agility type are identified.

\subsection{Agility types}

The results for the degree of agility perceived as being required by the warehouse designers for each distribution centre are set out in table 1. These represent to what extent the designers consciously tried to make the distribution centre agile in each respect.

[Insert table 1 about here]

For all eleven distribution centres at least one type of agility was considered to be "important" during the design process, whilst eight of the eleven involved an agility type that was considered "very important". The distribution centres covered in the research represented all agility types at least to an "average" level and therefore all agility types were investigated further, although the number of interviews for each agility type varied between 3 and 10, as set out in the right hand column of table 1 . Some agility types are thus represented more fully than others within this exploratory research.

The ability to be able to respond to variances in volume is well represented across the distribution centres, particularly with regard to growth, demand variance, and product life cycles. In fact, the capability to react to higher growth than anticipated was regarded as "very important" in 8 of the 11 distribution centre designs, and this aspect had the highest Likert score overall, with an average of 4.3. It should be noted that some of these sub-categories (e.g. growth) relate to total volume through the distribution centre, whilst others (e.g. 
promotions) relate to product mix variations. Some (e.g. seasonality and demand variance) may be a combination of both.

Responsiveness in terms of time was "important" for five of the distribution centres, although many are already operating a next day service level and therefore "rush orders" were considered the norm.

The ability to respond to different unit quantities (e.g. by allowing for variations in different order profiles from case to item quantities) was well represented in the distribution centres researched, although generally only at an "average" level. However, this aspect was considered "important" or "very important" in three of the designs

The categories of presentation and information were added to the list of agility types as a result of interview responses. Variances in presentation included for example the requirement to deliver different height pallets to some customers, whilst variances in information included the need to print labels, or send EDI messages, containing customer specific data fields.

On the inbound side, some of the distribution centres were seen as needing to respond to unplanned variations in deliveries from suppliers, particularly in terms of delivery volumes, times, presentation and information. Variable return characteristics were an issue for four of the distribution centre designs.

The requirements to be able to handle variances in unpredictable future growth, demand variance, product life cycles and unit quantities were regarded by the designers as being the 
most important for the distribution centres in question and therefore the responses to these agility types are examined further in this paper.

\subsection{Potential growth}

The interview results for the nine distribution centres where potential growth was considered to be an "average", "important" or "very important" aspect are set out in table 2. The two main ways in which the designers planned to accommodate potential growth were to provide extra land / buildings (for 6 of the 9 centres in the case of extra floor area) and to provide extra equipment (at 7 of the 9 centres). Extra land / buildings were viewed as being a slight to moderate increased cost, either as capital costs if purchased or as an operating cost if leased. Extra land would obviously need longer to convert to accommodate growth than an existing building. Extra floor area was immediately available for certain functions, such as block storage, but would need a medium to long term period for equipment installation. Extra height was often provided, normally to provide space for an additional level of mezzanine for expansion. The design of the building for modular expansion was seen as being necessary for some of the above features and this involved little extra cost in itself.

[Insert table 2 about here]

The provision of extra equipment capacity (e.g. on conveyors) was seen as slightly higher capital cost, but with no other implications. In particular, this method was immediately available to handle extra volume. A second approach, with even less initial capital cost implications, was to use equipment that could easily be upgraded (e.g. from manually operated cranes to automated cranes). This could eventually improve service levels at the 
time of upgrade (e.g. in terms of accuracy and damage levels). A third equipment approach was to use simpler equipment types (e.g. narrow aisle trucks or curve growing cranes) that could easily be added to if growth occurred. This often involved lower capital costs but higher operating costs, than more automated equipment.

For two of the distribution centres, the location near a readily available pool of labour was seen as important for the future recruitment of staff, should rapid growth occur. These two warehouses were deliberately located away from the traditional distribution "hot spots".

\subsection{Demand variance}

The most common way to design for demand variance was to provide extra equipment capacity (in 7 out of the 8 distribution centres relating to this type of variance), often combined with one or more flexible staffing solutions - either by means of flexible hours for existing staff or by employing agency staff (see table 3).

[Insert table 3 about here]

Examples of the extra equipment capacity included the capability of miniload (i.e. automated storage and retrieval systems for bins or cartons) to work well beyond average throughput levels, and the provision of extra pick and pack stations (to accommodate extra temporary staff). The provision of extra equipment capacity had a slight to medium capital cost implication, but was immediately available to handle variances and was viewed as doing this without any deterioration in service. One distribution centre involved the design of a picking system specifically for later expansion and this involved a slight increase in capital 
cost and a significant time delay in becoming available, if needed. A complementary approach at the same centre included the design of a sorter for flexible routing, which also involved a slight increase in capital cost but is available immediately.

All of the staffing options involved a slightly higher operating cost (e.g. owing to the higher wage rates associated with flexible hours or the higher rates of agency staff). A short time lag was generally necessary to arrange the extra staffing. Also, the use of non-permanent staff (i.e. part-time and agency staff) tended to lead to a deterioration in service level. In fact, staffing solutions to agility were the only areas that recorded a possible service level drop whilst handling the various types of variance in the study.

One interesting response to demand variability was to change the order picking process. The extra volumes at peak made it more cost effective to pick-to-order rather than to bulk pick. The optimum order picking process is generally a trade-off between efficient picking (as in bulk picking) and the avoidance of sortation (as in pick-to-order). The strategy was thus varied in line with order volume changes (i.e. being higher at peak compared to average throughput levels) leading to operating cost benefits.

\subsection{Life-cycle variance}

With life-cycle variances the total volumes passing through a warehouse may be constant but the product mix may change dramatically. For example, this could be due to catalogue changes or to rapid rates of obsolescence (as with many electronic items). In 5 of the 7 distribution centres relating to this variance, the accommodation of life-cycle variances resulted in extra equipment being planned (e.g. so that new pick faces could be opened for 
new product introductions). This normally led to higher capital and operating costs, but was available in a very short time-span (see table 4).

[Insert table 4 about here]

There was a range of other solutions used. Those that involved staffing had similar characteristics (in terms of cost, mobility and uniformity) to the staffing solutions described under demand variance above. Four distribution centres incorporated process or system improvements, to identify the life-cycle changes rapidly or to support the operation. These often had a cost implication. In one instance, the capital cost in bespoke software was regarded as being high, although operating costs and service levels were seen as benefiting from this investment.

\subsection{Unit quantity variance}

Unit quantity variance had an average Likert score of just above average (i.e. 3.2) but was a factor, at least at an "average" level, in 10 out of the 11 distribution centre designs. It was generally addressed in terms of equipment, by designing separate work-streams for item, case and pallet flows, as shown in table 5. For these 7 distribution centres, extra capacity was provided in all relevant areas of equipment to be able to handle potential peak workloads within each stream. This involved slight to moderate capital cost, but was also seen as providing operating cost efficiencies.

[Insert table 5 about here] 
In four distribution centres, specific equipment types were incorporated into the design to provide flexibility. These were generally less automated types (e.g. manually operated picking cranes), with lower capital costs but higher operating costs. One designer pointed out that staff flexibility was required to be able to achieve this responsiveness between workstreams (and that there was a training cost to this). Agility in this area incurred extra development costs for the computer systems in two instances (e.g. to recognise individual items, as well as cases and pallets).

Under all of these designs, the ability to respond to unit quantity variance was immediate and there was no anticipated reduction in service levels.

\subsection{Results for other agility types}

The above results just show four of the main categories of agility identified during the research. The results for all the agility types indicate that each category of agility is addressed by using a different mix of resources. For example, process and systems solutions were particularly important for the handling of time variance (e.g. rush orders), whilst staffing and equipment solutions were predominant for responding to seasonality.

\subsection{Consolidated results}

Across all of the agility types, the most common resource option employed to respond to future variance involved the use of equipment: 64 of the 141 instances (an instance being defined as one solution identified for one distribution centre). This was followed by information systems (26 instances), buildings (21) and staffing (20). Although warehouse 
design companies have an overall view of the how the future distribution centre should operate, the predominance of equipment may well reflect their prime area of responsibility and therefore the results should be regarded in that light. Further research would therefore be useful to examine the views of other participants in the design process (e.g. operational management, information systems management, and construction companies).

Another form of categorisation that could be superimposed on these response categories is that agility can be satisfied by:

- Providing extra capacity (e.g. additional floor area in the warehouse, or extra sortation machine capacity).

- Using additional resources when needed (e.g. temporary staff, or the upgrading of equipment).

- Employing flexible resources (e.g. staff on flexible hours, conveyors that can easily be rerouted, or software functionality that can be switched on and off as required).

Out of the total 141 instances recorded, 61 related to extra capacity (chiefly in relation to equipment and buildings), 23 to the use of additional resources (chiefly staff and equipment), and 57 to flexible resources (chiefly systems and equipment). The results for these different sets of categorisation are shown in table 6.

[Insert table 6 about here]

These different response categories have different implications in terms of capital and operating costs, as set out in table 7. The provision of extra capacity in terms of land, 
buildings, equipment and systems was regarded as incurring "slightly" to "moderately" higher capital costs, whilst extra staffing is reflected in higher operating costs. The design for additional building and equipment resources when needed was regarded as involving very slight increased capital costs. The only negative figure is for the use of flexible equipment, which was seen as less capital intensive, although incurring relatively higher operating costs (e.g. the use of a manual, rather than an automated, picking regime).

[Insert table 7 about here]

The mobility of resources also varied by response category, as shown in table 8 . Investment in extra land and the construction of additional buildings, on that land, were regarded as the longest response periods, whilst the provision of extra capacities for equipment, staff, and systems were regarded as being almost instantaneously available.

[Insert table 8 about here]

The uniformity (i.e. service) implications are shown in table 9. The negative figures refer to perceptions of improved service levels being provided. For example, one solution related to designing for the upgrade to a more automated solution when needed, which was viewed as improving accuracy when that occurred. A potential detrimental impact on service levels was seen as the use of additional staff resources to handle variances.

[Insert table 9 about here] 
The use of flexible resources reflects the "essence" of the aspirational ideal of agility and (with the exception of the capital cost of flexible systems solutions) these responses represented a way of handling variances with less than "slightly" increased costs (i.e. less than $+10 \%$ ), in a very "short" time frame (i.e. less than 3 weeks), and with no detriment to service levels. However, it should be noted that the use of flexible resources generally offers a way to cope with variability in mix, rather than in total volume. For changes in total volume, the use of excess capacity or additional resources is required. The former method generally involves higher capital costs, whereas the latter method takes longer to deploy.

\section{Conclusions}

The results largely substantiate the propositions put forward by Suarez et al. (1996, p.225) in relation to manufacturing flexibility, namely:

- "Different types of flexibility exist and are important to firms in different competitive situations." (This research indicates that different types of flexibility exist and are important to the distribution centres of different firms).

- "There are different ways of achieving each type of flexibility." (This research has also shown that some ways are common across different types of flexibility).

- "Different approaches to flexibility may have different costs and tradeoffs..." (This has been found in relation to capital costs, operating costs, mobility, and uniformity).

Whilst the question of agility needs to be addressed in overall supply chain terms (for example, by improving visibility and communication), the design of distribution centres can be a critical part of this. It is recognised that a mix of strategies needs to be adopted to 
become agile (e.g. Power et al. 2001) and this research reinforces that is also the case at the distribution centre level.

The challenge to warehouse designers is how to provide for agility whilst containing costs, providing a rapid response mechanism, and doing this without compromising customer service levels. The results have validated the agility types and the response categories developed in the research design, in as far as all the responses for these particular distribution centres could be classified within the framework that was devised.

As the agility type, range, mobility and uniformity can be specified as requirements at the outset of warehouse design (i.e. as requirements of the supply chain as a whole), then a warehouse design methodology can be developed starting with these elements. In line with the framework developed for this research, the next step would be to identify the resource options (e.g. equipment and staffing) that can meet the required agility types and then consider the alternative approaches to each of these (e.g. extra capacity or use of additional resources). These would need to be evaluated to ensure that they meet the range, mobility, and uniformity requirements, and, if so, the costs would then be calculated. Based on this information, the most appropriate agile approach could be adopted. This methodology is shown in figure 1.

[Insert figure 1 about here]

In general, there is often an increased cost to design for agility, although this is only perceived as being "slight" to "moderate". The nature of this cost may be in terms of a higher capital cost (e.g. over specification) or higher operating cost (e.g. for a manual rather 
than automated solution). The time needed to respond to variances depends on the nature of the design feature (e.g. ranging from the construction periods needed for building on extra land to the immediate availability of spare conveyor capacity). Generally, there is no perceived service level deterioration in handling agile responses within the design parameters, unless the use of temporary staff is planned. In fact, there are instances of anticipated service level benefits in some cases (e.g. where the ability to be able to respond to different unit quantities can be associated with the improved presentation of the goods to the customer).

This research provides a framework for considering agility in the design phase and is thus intended to develop knowledge in this area. It is intended to be of direct relevance to supply chain practitioners, as the methodology proposed could be used during the warehouse design process. The case study content provides an initial checklist of agile approaches, together with their cost, time and service implications. Further research is required to develop this framework and checklist more fully, and to extend this work into the actual operation of the distribution centres and to other aspects of the supply chain. In this way, a comprehensive approach to agility can be developed to incorporate the operational competencies and resources that are needed to provide the wider supply chain capabilities being sought. Such a framework would be a useful step to assist organisations that serve volatile markets to fulfil their agile aspirations.

\section{References}

Allen, N., Upping the stakes. Logistics Europe, March 2003, 23-26. 
Baker, P., Aligning distribution center operations to supply chain strategy. International Journal of Logistics Management, 2004, 15(1), 111-123.

Bal, J., Wilding, R. and Gundry, J., Virtual teaming in the agile supply chain. International Journal of Logistics Management, 1999, 10(2), 71-82.

Barney, J.B., Firm resources and sustained competitive advantage. Journal of Management, 1991, 17(1), 99-120.

Bodner, D.A., Govindaraj, T., Karathur, K.N., Zerangue, N.F., and McGinnins, L.F. A process model and support tools for warehouse design. Proceedings of the 2002 NSF design, service and manufacturing grantees and research conference, 2002.

Childerhouse, P. and Towill, D., Engineering supply chains to match customer requirements. Logistics Information Management, 2000, 13(6), 337-345.

Christopher, M., The agile supply chain: competing in volatile markets. Industrial Marketing Management, 2000, 29, 37-44.

Christopher, M., Logistics and Supply Chain Management, $3^{\text {rd }}$ edition, 2005 (Pearson: Harlow).

Christopher, M. and Towill, D., An integrated model for the design of agile supply chains. International Journal of Physical Distribution \& Logistics Management, 2001, 31(4), 235246. 
Drucker, P., The economy's power shift. The Wall Street Journal, 1992, September $24^{\text {th }}$.

Establish Inc / Herbert W. Davis \& Co., Logistics Cost and Service 2005, presented at Council of Supply Chain Management Professionals Conference, 2005.

Frazelle, E.H., Supply Chain Strategy: the Logistics of Supply Chain Management, 2002a (McGraw-Hill: New York).

Frazelle, E.H., World-Class Warehousing and Material Handling, 2002b (McGraw-Hill: New York).

Harrison, A. and van Hoek R., Logistics Management and Strategy, $2^{\text {nd }}$ edition, 2005 (Pearson: Harlow).

Hassan, M., A framework for the design of warehouse layout. Facilities, 2002, 20(13/14), $432-440$.

Herer, Y. T., Tzur, M. and Yucesan, E., Transshipments: an emerging inventory recourse to achieve supply chain leagility. International Journal of Production Economics, 2002, 80, 201-212.

Higginson, J.K. and Bookbinder, J.H., Distribution centres in supply chain operations. In Logistics Systems: Design and Optimization, edited by Langevin, A.L. and Riopel, D., pp. 6791, 2005 (Springer: New York). 
Koste, L.L. and Malhotra, M.K., A theoretical framework for analyzing the dimensions of manufacturing flexibility. Journal of Operations Management, 1999, 18, 75-93.

Maltz, A. and DeHoratius, N., Warehousing: The Evolution Continues, 2004 (Warehousing Education and Research Council, Oak Brook).

Mason-Jones, R., Naylor, B. and Towill, D.R., Engineering the leagile supply chain. International Journal of Agile Management Systems, 2000, 2(1), 54-61.

Mason-Jones, R. and Towill, D.R., Total cycle time compression and the agile supply chain. International Journal of Production Economics, 1999, 62, 61-73.

Matthews, R., Automated flexibility. Industrial Handling \& Storage, June/July 2001, 12-19.

Naylor, J. B., Naim, M.M. and Berry, D., Leagility: integrating the lean and agile manufacturing paradigms in the total supply chain. International Journal of Production Economics, 1999, 62, 107-118.

Office for National Statistics, Annual Business Inquiry, Sections C to G, $16^{\text {th }}$ December 2005.

Pfohl, H-C., Zollner, W. A. and Weber, N., Economies of scale in customer warehouses: theoretical and empirical analysis. Journal of Business Logistics, 1992, 13(1), 95-124. 
Power, D.J., Sohal, A.S. and Rahman, S-U., Critical success factors in agile supply chain management: an empirical study. International Journal of Physical Distribution \& Logistics Management, 2001, 31(4), 247-265.

Prater, E., Biehl, M. and Smith, M. A., International supply chain agility: tradeoffs between flexibility and uncertainty. International Journal of Operations \& Production Management, 2001, 21(5/6), 823-839.

Rouwenhorst, B., Reuter, B., Stockrahm, V., van Houtum, G., Mantel, R., and Zijm, W., Warehouse design and control: framework and literature review. European Journal of Operational Research, 2000, 122(3), 515-533.

Rowley, J., The Principles of Warehouse Design, $2^{\text {nd }}$ edition, 2000 (The Institute of Logistics \& Transport: Corby).

Rushton, A., Oxley, J., and Croucher, P., The Handbook of Logistics and Distribution Management, $2^{\text {nd }}$ edition, 2000 (Kogan Page: London).

Stratton, R. and Warburton, R.D.H., The strategic integration of agile and lean supply. International Journal of Production Economics, 2003, 85, 183-198.

Suarez, F.F., Cusumano, M.A. and Fine, C.H., An empirical study of manufacturing flexibility in printed circuit board assembly. Operations Research, 1996, 44(1), 223-240. 
Tarn, J.M., Razi, M.A., Wen, H.J. and Perez Jr., A.A., E-fulfillment: the strategy and operational requirements. Logistics Information Management, 2003, 16(5), 350-362.

Upton, D. M., The management of manufacturing flexibility. California Management Review, Winter 1994, 72-89.

Van Hoek, R. I., Epilogue: moving forward with agility. International Journal of Physical Distribution \& Logistics Management, 2001, 31(4), 290-300.

Van Hoek, R. I., Harrison, A. and Christopher, M., Measuring agile capabilities in the supply chain. International Journal of Operations \& Production Management, 2001, 21(1/2), 126147.

Zhang, Q., Vonderembse, M.A. and Lim, J-S., Value chain flexibility: a dichotomy of competence and capability. International Journal of Production Research, 2002, 40(3), 561583. 


\begin{tabular}{|c|c|c|c|c|c|c|c|c|c|c|c|c|c|}
\hline & \multicolumn{11}{|c|}{ Distribution Centre Likert Scores } & \multirow{2}{*}{$\begin{array}{c}\text { Average } \\
\text { Likert } \\
\text { score }\end{array}$} & \multirow{2}{*}{$\begin{array}{c}\text { No. of DCs } \\
\text { where score } \\
\text { is "3" or } \\
\text { above }\end{array}$} \\
\hline & $\mathbf{A}$ & B & $\mathrm{C}$ & D & $\mathbf{E}$ & $\mathbf{F}$ & $\mathbf{G}$ & $\mathbf{H}$ & $\mathbf{I}$ & $\mathbf{J}$ & $\mathbf{K}$ & & \\
\hline \multicolumn{14}{|l|}{ Volume } \\
\hline Growth & 5 & 3 & 5 & 5 & 5 & 2 & 5 & 2 & 5 & 5 & 5 & 4.3 & 9 \\
\hline $\begin{array}{l}\text { Demand } \\
\text { variance }\end{array}$ & 5 & 3 & 2 & 3 & 5 & 3 & 4 & 3 & 2 & 2 & 4 & 3.3 & 8 \\
\hline Seasonality & 5 & 1 & 2 & 2 & 3 & 4 & 4 & 1 & 5 & 1 & 1 & 2.6 & 5 \\
\hline Life cycles & 5 & 1 & 2 & 2 & 4 & 4 & 4 & 4 & 5 & 1 & 3 & 3.2 & 7 \\
\hline Promotions & 1 & 1 & 4 & 2 & 2 & 1 & 3 & 3 & 2 & 1 & 1 & 1.9 & 3 \\
\hline \multicolumn{14}{|l|}{ Time } \\
\hline Rush orders & 3 & 4 & 1 & 4 & 1 & 1 & 1 & 4 & 4 & 1 & 4 & 2.5 & 6 \\
\hline \multicolumn{14}{|l|}{$\begin{array}{l}\text { Unit } \\
\text { quantities }\end{array}$} \\
\hline $\begin{array}{l}\text { Items vs cases } \\
\text { vs pallets }\end{array}$ & 5 & 3 & 3 & 4 & 4 & 3 & 1 & 3 & 3 & 3 & 3 & 3.2 & 10 \\
\hline \multicolumn{14}{|l|}{ Presentation } \\
\hline Outbound & 4 & 1 & 3 & 4 & 1 & 1 & 1 & 4 & 4 & 1 & 2 & 2.4 & 5 \\
\hline \multicolumn{14}{|l|}{ Information } \\
\hline $\begin{array}{l}\text { Customised } \\
\text { information }\end{array}$ & 4 & 1 & 1 & 4 & 1 & 1 & 1 & 2 & 1 & 3 & 3 & 2.0 & 4 \\
\hline \multicolumn{14}{|l|}{ Inbound } \\
\hline Volume/time & 1 & 1 & 4 & 4 & 4 & 3 & 2 & 2 & 2 & 1 & 3 & 2.5 & 5 \\
\hline $\begin{array}{l}\text { Items vs cases } \\
\text { vs pallets }\end{array}$ & 1 & 3 & 3 & 3 & 2 & 1 & 1 & 2 & 1 & 1 & 3 & 1.9 & 4 \\
\hline Presentation & 3 & 1 & 2 & 4 & 2 & 1 & 2 & 4 & 4 & 3 & 2 & 2.5 & 5 \\
\hline Information & 1 & 1 & 2 & 4 & 3 & 1 & 4 & 3 & 3 & 1 & 2 & 2.3 & 5 \\
\hline \multicolumn{14}{|l|}{ Returns } \\
\hline $\begin{array}{l}\text { Returned } \\
\text { goods }\end{array}$ & 1 & 1 & 1 & 4 & 4 & 1 & 1 & 4 & 4 & 1 & 2 & 2.2 & 4 \\
\hline
\end{tabular}

5 = "very high", 4 = "high", 3 = "average", 2 = "low", 1 = "very low or none".

Table 1: Degree of agility perceived as being required for each distribution centre 


\begin{tabular}{|c|c|c|c|c|c|}
\hline Resource & $\begin{array}{c}\text { Number of } \\
\text { Distribution } \\
\text { Centres } \\
\text { (out of 9) } \\
\end{array}$ & Capital Cost & $\begin{array}{c}\text { Operating } \\
\text { Cost }\end{array}$ & $\begin{array}{l}\text { Mobility } \\
\text { (time) }\end{array}$ & $\begin{array}{c}\text { Uniformity } \\
\text { (service level) }\end{array}$ \\
\hline \multicolumn{6}{|l|}{ Building / land } \\
\hline Extra land & 4 & 1.3 & 0 & 3.0 & 0 \\
\hline Extra floor area & 6 & 1.7 & 0.5 & 2.5 & 0 \\
\hline Extra height & 4 & 1.0 & 0.3 & 2.0 & 0 \\
\hline Extra docks & 1 & 1.0 & 0 & 0 & 0 \\
\hline Modular design & 3 & 0.3 & 0 & 3.0 & 0 \\
\hline \multicolumn{6}{|l|}{ Equipment } \\
\hline Extra capacity & 7 & 1.1 & 0 & 0 & 0 \\
\hline $\begin{array}{l}\text { Upgradeable } \\
\text { equipment }\end{array}$ & 4 & 0.5 & 0 & 2.0 & -0.5 \\
\hline Equipment type & 5 & -0.6 & 0.6 & 1.4 & 0 \\
\hline \multicolumn{6}{|l|}{ Staffing } \\
\hline Location & 2 & 0 & -1.0 & 0 & 0 \\
\hline Shift capacity & 1 & 2.0 & -2.0 & 2.0 & 0 \\
\hline \multicolumn{6}{|l|}{ Process / systems } \\
\hline Systems capacity & 1 & 1.0 & 0 & 0 & 0 \\
\hline Expandability & 1 & 1.0 & 0 & 1.0 & 0 \\
\hline Process capability & 1 & 1.0 & 1.0 & 0 & 0 \\
\hline
\end{tabular}

\section{Key:}

Capital cost, operating cost and uniformity figures are average Likert scores on the following scale: $3=$ "much higher", $2=$ "moderately higher", 1 = "slightly higher", 0 = "same", -1 = "slightly lower", -2 = "moderately lower", -3 = "much lower".

Mobility figures are average Likert scores on the following scale:

$0=$ "immediately available", 1 = "short-term", 2 = "medium-term", 3 = "long-term".

Table 2: Agile resources to accommodate potential growth 


\begin{tabular}{|c|c|c|c|c|c|}
\hline Resource & $\begin{array}{c}\text { Number of } \\
\text { Distribution } \\
\text { Centres } \\
\text { (out of 8) } \\
\end{array}$ & Capital Cost & $\begin{array}{c}\text { Operating } \\
\text { Cost }\end{array}$ & $\begin{array}{l}\text { Mobility } \\
\text { (time) }\end{array}$ & $\begin{array}{l}\text { Uniformity } \\
\text { (service } \\
\text { level) }\end{array}$ \\
\hline \multicolumn{6}{|l|}{ Equipment } \\
\hline Extra capacity & 7 & 1.6 & 0.3 & 0 & 0 \\
\hline Design for expansion & 1 & 1.0 & 0 & 3.0 & 0 \\
\hline Design for flexible routes & 1 & 1.0 & 0 & 0 & 0 \\
\hline \multicolumn{6}{|l|}{ Staff } \\
\hline Flexible hours & 2 & 0 & 1.0 & 0.5 & 0 \\
\hline Part-time staff & 1 & 0 & 1.0 & 0 & 1.0 \\
\hline Extra shifts & 1 & 0 & 1.0 & 1.0 & 0 \\
\hline Agency staff & 3 & 0 & 1.0 & 1.0 & 0.7 \\
\hline \multicolumn{6}{|l|}{ Process } \\
\hline Pick process flexibility & 1 & 0 & -1.0 & 0 & 0 \\
\hline
\end{tabular}

Table 3: Agile resources to accommodate demand variance 


\begin{tabular}{|c|c|c|c|c|c|}
\hline Resource & $\begin{array}{c}\text { Number of } \\
\text { Distribution } \\
\text { Centres } \\
\text { (out of } 7)\end{array}$ & Capital Cost & $\begin{array}{c}\text { Operating } \\
\text { Cost }\end{array}$ & $\begin{array}{c}\text { Mobility } \\
\text { (time) }\end{array}$ & $\begin{array}{c}\text { Uniformity } \\
\text { (service } \\
\text { level) }\end{array}$ \\
\hline \multicolumn{6}{|l|}{ Building } \\
\hline Extra floor space & 1 & 2.0 & 0 & 0 & 0 \\
\hline \multicolumn{6}{|l|}{ Equipment } \\
\hline Extra capacity & 5 & 1.8 & 0.8 & 0.2 & 0 \\
\hline Equipment type & 1 & -2.0 & 2.0 & 1.0 & 0 \\
\hline \multicolumn{6}{|l|}{ Staff } \\
\hline Flexible hours & 1 & 0 & 1.0 & 0 & 0 \\
\hline Part-time staff & 1 & 0 & 1.0 & 0 & 0 \\
\hline Temporary staff & 1 & 0 & 1.0 & 1.0 & 1.0 \\
\hline \multicolumn{6}{|l|}{ Process } \\
\hline Life-cycle identification & 1 & 0 & 1.0 & 1.0 & 0 \\
\hline \multicolumn{6}{|l|}{ Systems } \\
\hline Bespoke software & 1 & 3.0 & -1.0 & 0 & -1.0 \\
\hline Life-cycle identification & 1 & 1.0 & 1.0 & 1.0 & 0 \\
\hline Support for temporary staff & 1 & 1.0 & 1.0 & 0 & 0 \\
\hline
\end{tabular}

Table 4: Agile resources to accommodate life-cycle variance 


\begin{tabular}{|c|c|c|c|c|c|}
\hline Resource & $\begin{array}{c}\text { Number of } \\
\text { Distribution } \\
\text { Centres } \\
\text { (out of 10) }\end{array}$ & Capital Cost & $\begin{array}{c}\text { Operating } \\
\text { Cost }\end{array}$ & $\begin{array}{c}\text { Mobility } \\
\text { (time) }\end{array}$ & $\begin{array}{c}\text { Uniformity } \\
\text { (service } \\
\text { level) }\end{array}$ \\
\hline \multicolumn{6}{|l|}{ Equipment } \\
\hline Work-stream capacity & 7 & 1.3 & -0.3 & 0 & -0.1 \\
\hline Upgradeable equipment & 1 & 1.0 & 0 & 0 & 0 \\
\hline Equipment type & 4 & -0.8 & 1.0 & 0 & 0 \\
\hline \multicolumn{6}{|l|}{ Staff } \\
\hline Flexibility & 1 & 0 & 1.0 & 0 & 0 \\
\hline \multicolumn{6}{|l|}{ Systems } \\
\hline Bespoke WMS & 1 & 2.0 & 0 & 0 & 0 \\
\hline Work-stream complexity & 1 & 1.0 & 0 & 0 & 0 \\
\hline
\end{tabular}

Table 5: Agile resources to accommodate unit quantity variance 


\begin{tabular}{lrrrr}
\hline Resource & $\begin{array}{c}\text { Extra } \\
\text { capacity }\end{array}$ & $\begin{array}{c}\text { Additional } \\
\text { resources } \\
\text { when } \\
\text { needed }\end{array}$ & $\begin{array}{c}\text { Flexible } \\
\text { resources }\end{array}$ & Total \\
\hline Land & 4 & 0 & 0 & 4 \\
\hline Building & 17 & 4 & 0 & 21 \\
\hline Equipment & 37 & 7 & 20 & 64 \\
\hline Staffing & 2 & 11 & 7 & 20 \\
\hline Systems & 1 & 1 & 24 & 26 \\
\hline Process & 0 & 0 & 6 & 6 \\
\hline Total & 61 & 23 & 57 & 141 \\
\hline
\end{tabular}

Table 6: Number of instances recorded 


\begin{tabular}{lrrr}
\hline Resource & $\begin{array}{c}\text { Extra } \\
\text { capacity }\end{array}$ & $\begin{array}{c}\text { Additional } \\
\text { resources } \\
\text { when needed }\end{array}$ & $\begin{array}{c}\text { Flexible } \\
\text { resources }\end{array}$ \\
\hline Land & $1.3 ; 0.0$ & - & - \\
\hline Building & $1.4 ; 0.4$ & $0.3 ; 0.0$ & $-0.4 ; 0.7$ \\
\hline Equipment & $1.4 ; 0.2$ & $0.6 ; 0.0$ & $0.3 ; 0.0$ \\
\hline Staffing & $0.0 ; 1.0$ & $0.0 ; 1.1$ & $1.1 ; 0.2$ \\
\hline Systems & $1.0 ; 0.0$ & $1.0 ; 0.0$ & $0.5 ; 0.3$ \\
\hline Process & - & - & 0.3 \\
\hline Kers
\end{tabular}

Key:

Capital cost implication shown first; then operating cost implication

Table 7: Capital and operating cost implications of each approach 


\begin{tabular}{lrrr}
\hline Resource & $\begin{array}{c}\text { Extra } \\
\text { capacity }\end{array}$ & $\begin{array}{c}\text { Additional } \\
\text { resources } \\
\text { when needed }\end{array}$ & $\begin{array}{c}\text { Flexible } \\
\text { resources }\end{array}$ \\
\hline Land & 3.0 & - & - \\
\hline Building & 1.4 & 3.0 & - \\
\hline Equipment & 0.1 & 2.0 & 0.4 \\
\hline Staffing & 0.0 & 0.7 & 0.4 \\
\hline Systems & 0.0 & 1.0 & 0.1 \\
\hline Process & - & - & 0.5 \\
\hline
\end{tabular}

Table 8: Mobility (time) implication of each approach 


\begin{tabular}{lrrr}
\hline Resource & $\begin{array}{c}\text { Extra } \\
\text { capacity }\end{array}$ & $\begin{array}{c}\text { Additional } \\
\text { resources } \\
\text { when needed }\end{array}$ & $\begin{array}{c}\text { Flexible } \\
\text { resources }\end{array}$ \\
\hline Land & 0.0 & - & - \\
\hline Building & 0.0 & 0.0 & - \\
\hline Equipment & -0.1 & -0.3 & 0.0 \\
\hline Staffing & -0.5 & 0.4 & 0.0 \\
\hline Systems & 0.0 & 0.0 & -0.2 \\
\hline Process & - & - & -0.2 \\
\hline
\end{tabular}

Table 9: Uniformity (service) implication of each approach 


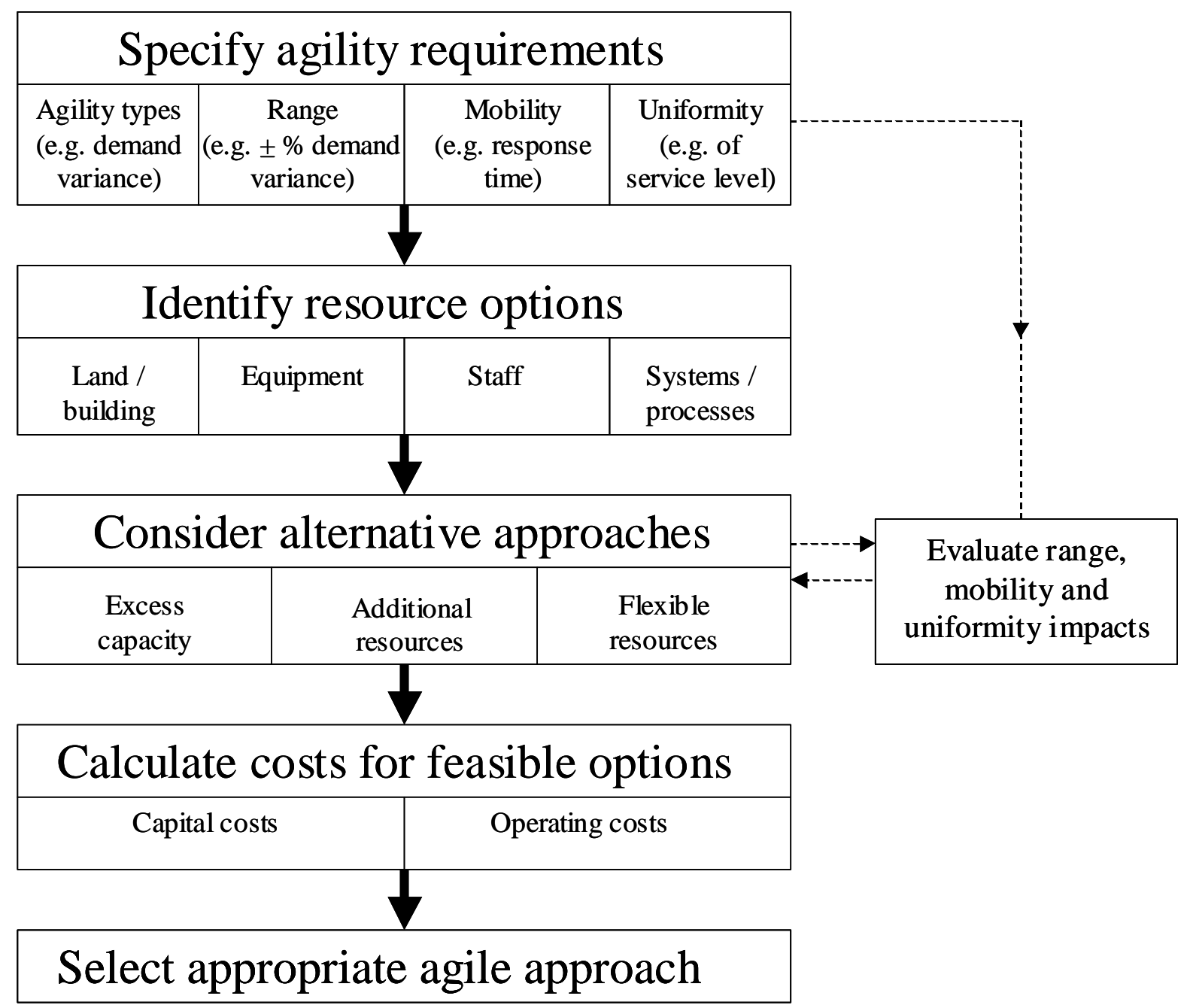

Figure 1: Methodology for selecting the appropriate agile approach to warehouse design 